\title{
CARDIOMED CORONARY FLOW METER FOR PREVENTION OF EARLY OCCLUSION IN AORTOCORONARY BYPASS GRAFTING
}

\author{
Marek Gwozdziewicz
}

Department of Cardiac Surgery, Teaching Hospital, 77500 Olomouc, Czech Republic

Received: May 5, 2004; Accepted (with revisions): June 29, 2004

Key words: Aortocoronary bypass/Sequential/Occlusion/Flow measurement

Introduction: The number of patients undergoing technically demanding off-pump myocardial revascularization is increasing, these days. Some researchers question the quality of the aortocoronary bypasses done on the beating heart and consequently their good patency.

Material and methods: 50 consecutive patients underwent off pump coronary surgery using sequential bypass technique, at our department. The quality of constructed grafts was evaluated using the CardioMed Trace System (CM 4008, Medi-Stim As, Oslo, Norway) (TTFM). Results: All sequential bypasses showed good per-operative quality with a mean flow of $69.4 \mathrm{ml} / \mathrm{min}$.

Conclusion: TTFM seems to be an effective tool for the per-operative aortocoronary bypass patency verification and should help to prevent early graft occlusion.

Abbreviations: TTFM transit time flow meter

\section{INTRODUCTION}

Coronary artery bypass grafting is one approach to management of ischemic heart disease. Recently, the number of patients undergoing off-pump surgery has increased and this has provoked discussion about the potential risk of lower quality of the anastomoses. Performing a vascular anastomosis on the beating heart is technically more demanding and, if it fails, complications such as acute intra-operative myocardial ischemia or reduced graft patency may ensue.

A technique permitting intraoperative measurement of coronary graft flow and thus indirect assessment of the quality of the anastomosis has recently been adopted in our Department. It utilizes the CardioMed Trace System (CM 4008, Medi-Stim As, Oslo, Norway), namely a Transit Time Flow Meter (TTFM). This ultrasoundbased device has many advantages over the classical Doppler measurement system. TTFM measurements are theoretically independent of internal or external vessel diameter and vessel shape. The probe does not have to be in direct contact with the vessel and, in contrast to previous electromagnetic flow meters, calibration is not required. The result is not dependent on the angle between vessel and probe, vessel diameter, or haematocrit value.

The usefulness of this method for evaluation of coronary graft flow in cardiovascular surgery has been reported by several authors ${ }^{1,2,3}$. The greatest advantage of the TTFM is the ease with which a technical error is detected, i.e., anastomotic stenosis. From the shape and course of the flow curve and flow values obtained, it is possible, with a great deal of certainty, to identify a "problem" associated with the anastomosis in an apparently patent graft.

The revision rate of bypass grafts after intraoperative angiography is estimated to be up to 20 to $30 \%{ }^{4,5,6}$, which is higher than the reported number of acute graft occlusions (5\%) or the number of early re-operations for acute occlusion $(6 \%)^{7}$. Since a technical error is often the cause of graft non-patency, the TTFM provides a convenient tool for the prevention of early occlusions in aortocoronary bypass grafts.

Blood flow in a vessel is directly proportional to blood pressure and indirectly proportional to vascular resistance that depends on a number of factors $\left(\mathrm{R}=8 \mathrm{n} 1 / \Pi \mathrm{r}^{4}\right)$. Therefore, the absolute flow value is not a reliable indicator of the quality of the anastomosis because, even in a fully patent graft, flow may be low due to high vascular resistance. In addition to blood flow measurement, the TTFM also provides several other values relevant to blood flow and vascular resistance, i.e.

PI, pulsatility index, which is obtained by dividing the difference between the maximum and the minimum flow by the value of the mean flow.

F-D/T, ratio of the diastolic flow value to the mean flow value.

FFT, fast Furier's transformation of the flow curve

PI values, expressed in real numbers, are good indicators of both graft flow and graft patency and they should not be higher than $5.0^{8,9}$. Some writers recommend coronary graft revision at PI $\geq 2.5$, which is a much lower value $^{10}$. The F-D/T value is also regarded as a reliable 
indicator of the quality of the anastomosis and, in a perfectly sutured anastomosis, it should exceed $55 \%{ }^{11}$. A fast Furier's transformation of the flow curve at values over 1.0 indicates a patent coronary graft, while values lower than 1.0 are suggestive of a stenotic or occluded graft $^{12}$.

In the study performed at our department using TTFM, the quality of the especially technically demanding sequential aortocoronary bypasses done on the beating heart was established by the per-operative measurement of their flow and pulsatility indexes.

\section{MATERIAL AND METHODS}

Between January 2003 and February 2004, 50 consecutive patients underwent off pump coronary surgery using sequential bypass technique. The examined group of patients comprised 36 men and 14 women with a mean age of $69.7 \pm 9.0$. Preoperative characteristics of the patients are summarized in Table 1.

Table 1. Preoperative characteristics ${ }^{\mathrm{a}, \mathrm{b}}$.

\begin{tabular}{|l|l|}
\hline Mean age & $69.7 \pm 9.0$ \\
\hline Diabetes & $22(44)$ \\
\hline Hypertension & $41(82)$ \\
\hline Hypercholesterolemia & $29(58)$ \\
\hline Previous cerebrovascular accident & $7(14)$ \\
\hline $\begin{array}{l}\text { Number of diseased vessels } \\
\text { Left main } \\
\text { Triple vessel }\end{array}$ & $11(22)$ \\
\hline Mean LV ejection fraction & $40(80)$ \\
\hline Previous failed PCI/stent & $52 \pm 9.4$ \\
\hline
\end{tabular}

${ }^{\text {a }} \mathrm{LV}$, left ventricle; PCI, percutaneous coronary intervention

${ }^{\mathrm{b}}$ Numbers in parentheses are in percentages

\section{Surgical technique}

In all cases median sternotomy was used for surgical access to the heart. Each patient was partially heparinized. Stabilization of the heart was achieved by suction-based tissue stabilizers - Axius vaccum 2 and Axius expose 3 (Guidant, Santa Clara, CA USA). For better surgical exposure a modified "Lima" pericardial traction stitch was also used. To maintain distal myocardial perfusion during the operation, all anastomoses were constructed using intra-coronary shunts (Axius coronary shunt, Guidant, Santa Clara, CA USA). To create a sequential aortocoronary bypass, a distal end-to-side, proximal vein to ascending aorta and proximal, sequential side-to-side anastomosis was performed. After completion of the bypass the blood flows and their PI values were measured.
Flow through the whole sequential bypass (T) and flows through the both proximal (P) and distal (D) segment of the graft were examined.

\section{RESULTS}

In the group of 50 patients, on average 3.6 grafts per patient were completed. Each patient had mammary to LAD bypass as one of the grafts. None of the sequential grafts required revision due to technical error. If this occurred it would have manifested as low values of flow and high PI numbers or by per-operative development of the myocardial ischemia. The average flow through the sequential bypass was equal to $69.4 \mathrm{ml} / \mathrm{min}$. The flows through the proximal and distal segment of the sequential graft were, on average, 36.9 and $39.0 \mathrm{ml} / \mathrm{min}$, respectively. All measured PI values remained below the approved level of 5.0 .

The results of measurement are shown in Table 2.

Table 2. Blood flows, pulsatility indexes and hemodynamic parameters ${ }^{\mathrm{a}}$.

\begin{tabular}{|c|c|c|c|c|}
\hline & $\begin{array}{c}\text { Flow } \\
\mu \pm \mathrm{SD} \\
{\left[\mathrm{ml}_{\left.\mathrm{min}^{-1}\right]}\right.}\end{array}$ & $\begin{array}{c}\text { PI } \\
\mu \pm \mathrm{SD}\end{array}$ & $\begin{array}{c}\text { MAP } \\
\mu \pm \mathrm{SD} \\
{[\mathrm{mmHg}]}\end{array}$ & $\begin{array}{c}\mu \pm \mathrm{SD} \\
{\left[\mathrm{min}^{-1}\right]}\end{array}$ \\
\hline $\mathrm{T}$ & $69.4 \pm 29.0$ & $1.8 \pm 0.4$ & $70.6 \pm 9.1$ & $75.2 \pm 17.5$ \\
\hline $\mathrm{P}$ & $36.9 \pm 18.7$ & $2.4 \pm 0.9$ & $70.6 \pm 9.0$ & $75.1 \pm 17.1$ \\
\hline $\mathrm{D}$ & $39.0 \pm 23.7$ & $2.3 \pm 1.0$ & $70.9 \pm 9.2$ & $75.6 \pm 17.1$ \\
\hline
\end{tabular}

${ }^{a} \mathrm{~T}$, flow through the whole sequential bypass; $\mathrm{P}$, flow through the proximal segment of sequential bypass; $D$, flow through the distal segment of sequential bypass; PI, pulsatility index; MAP, mean arterial pressure; HR, heart rate; $\mu$, mean value; $\mathrm{SD}$, standard deviation

\section{DISCUSSION}

Aortocoronary bypass surgery has been performed for almost half a century, now. Despite substantial improvement in surgical technique the operative treatment of the ischemic heart disease is still only palliative. For this reason graft patency is a very important issue and is strictly followed by many researchers. Regarding the literature $50 \%$ of venous bypasses are closed and $25 \%$ have significant atherosclerotic lesions 10 years later. Closure of 10 to $15 \%$ of saphenous vein grafts in the first month, followed by another 5 to $10 \%$ in the next 11 months is mostly secondary to a failure in surgical technique $^{13}$. This could be caused by an angulation of the graft, linear tension due to insufficient graft length but most frequently because of failure in the construction of the anastomosis itself. The probability of technical error is even grater when sequential bypass technique is used. 
This technique involves connecting a conduit to more than one coronary artery.

Introduction of off pump coronary surgery has provoked discussions about the potential risk of lower quality of the anastomoses. Some authors have pointed out that, in off pump coronary artery bypass grafting, the quality of anastomoses and, consequently, graft patency may be reduced $^{14}$.

The per-operative measurement of the bypass flow and its pulsatility index provided by the TTFM seems to be an effective tool for immediate detection of poor quality of the constructed aorotocoronary grafts ${ }^{2,8,9,11,12}$. In the presented study, 50 consecutive patients underwent off pump coronary surgery using sequential bypass technique, at our department. All grafts showed very good quality, which is essential for prevention of early graft occlusion.

\section{CONCLUSION}

We believe that presented method of graft patency verification is a great contribution to cardiovascular surgery and a means of preventing early coronary graft occlusion. It is possible that one day the aortocoronary graft's flow and PI values will be a routine part of the surgical protocol in every patient.

\section{REFERENCES}

1. Canver CHC. (1990) Ultrasonic assessment of internal thoracic artery graft flow in the revascularized heart. Ann Thorac Surg 58, $135-138$.
2. Walpoth B H. (1998) Transit-Time flow measurement for detection of early graft failure during myocardial revascularization. Ann Thorac Surg 66, 1097-1100.

3. Laustsen J. (1996) Validation of a new transit time ultrasound flow meter in man. Eur J Cardio-thorac Surg 12, 91-96.

4. Lazzara RR. (1997) Intraoperative angiography during minimally invasive direct coronary artery bypasses operations. Ann Thorac Surg 64, 1725-1727.

5. Barstad RM. (1997) Intraoperative angiography in minimally invasive direct coronary artery bypass grafting. Ann Thorac Surg 64, 1835-1839.

6. Moshkovitz Y. (1995) Coronary artery bypass without cardiopulmonary bypass: analysis of short-term and mid-term outcome in 220 patients. J Thorac Cardiovasc Surg 110, 979-987.

7. Calafiore AM. (1998) Midterm results after minimally invasive coronary surgery (LAST operation). J Thorac Cardiovasc Surg $115,763-771$

8. D Ancona G. (2001) Is intraoperative measurement of coronary blood flow a good predictor of graft patency? Eur J Cardio-thorac Surg 20, 1075-1076.

9. D Ancona G. (2000) Graft revision after transit time flow measurement in off pump coronary artery bypass grafting. Eur J Cardiothorac Surg 17, 287-293.

10. Di Giammarco G. (1999) Myocardial revascularization without cardiopulmonary bypass-presented at symposium: State of the art in emerging coronary revascularization EACTS. Glasgow Scotland September 4.

11. Morota T. (2002) Intraoperative evaluation of coronary anastomosis by transit-time ultrasonic flow measurement. Ann Thorac Surg 73, 1446-1450.

12. Takami Y. (2001) A simple method to determine anastomotic quality of coronary artery bypass grafting in the operating room J Thorac Cardiovasc Surg 9, 499-503.

13. Barner HB. Techniques of Myocardial Revascularization In: Edmunds LH Jr. Cardiac surgery in the adult. McGraw-Hill, (1997). Pp. 500-502.

14. Ki-Bong K, Cheong L, Cheul L, In-Ho Ch, Byung-Hee O, Myoung-Mook L, Young-Bae P. (2001) Off-pump coronary bypass may decrease patency of saphenous vein grafts Ann Thorac Surg 72, S1033-S1037. 